\title{
ESTRATÉGIAS DE MARKETING NA SERRA DO CAPARAÓ
}

\author{
MARKETING STRATEGIES IN SERRA DO CAPARAÓ
}
Rafael Neves Machado ${ }^{1}$, Ivonete Faria Castelani², Paulo Roberto da Silva Junior ${ }^{3}$, Elisângela Freitas da Silva ${ }^{4}$

1 Universidade do Estado de Minas Gerais - Unidade Carangola, Brasil, faell.machado@hotmail.com
2 Universidade do Estado de Minas Gerais - Unidade Carangola, Brasil, ivonetecastelani@hotmail.com

3 Universidade do Estado de Minas Gerais - Unidade Carangola, Brasil, cunha@hotmail.com 4 Universidade do Estado de Minas Gerais - Unidade Carangola, Brasil, elis_freitass@hotmail.com

\section{A R T I C L EI N F O}

Article history:

Received 2019-07-21

Accepted 2019-12-14

Available online 2019-12-14
Palavras-chave: Estratégias de marketing. Marketing de lugares. Turismo.

Keywords: Marketing strategies. Seat Marketing. Tourism.

RESUMO. Tendo em vista a forte influência do marketing sobre as decisões dos consumidores, o marketing de imagem, de atrações, de infraestrutura e de pessoas são algumas das estratégias que podem ser desenvolvidas para obter os resultados. Marketing de lugares colabora para o desenvolvimento econômico de uma região, mostrando que a ferramenta quando bem implementada atrai interesses diversos potencializando e agregando valor ao lugar, fazendo com que seu público alvo tenha interesse em conhecer o produto. O estudo tem como objetivo identificar as estratégias de marketing realizadas pelo setor público e privado para o desenvolvimento dos municípios de Alto Caparaó, Dores do Rio Preto e Espera Feliz, mais especificamente verificar a atuação, identificando assim as ações realizadas e sugerir quais ainda poderiam ser aplicadas. A metodologia aplicada foi definida como, quanto aos fins, descritiva, quanto aos meios, qualitativa, com pesquisa bibliográfica e realização de entrevistas com roteiro estruturado, com os Secretários de Turismo dos três municípios. Como resultado, os entrevistados relataram ações desempenhadas pelos municípios que impactam direta e indiretamente no desenvolvimento socioeconômico local da região. Foi constatado que os municípios têm uma forte parceria para juntos fortalecerem o turismo de toda a região e ressaltado ser importante manter os turistas o maior tempo possível, inclusive desfrutando de todos os atrativos disponibilizados, contribuindo com o crescimento de satisfação à todas as esferas comerciais dos municípios.

ABSTRACT. Given the strong influence of marketing on consumer decisions, image, attraction, infrastructure, and people marketing are some of the strategies that can be developed to deliver results. Place marketing contributes to the economic development of a region by showing that the tool, when wellimplemented, attracts a variety of interests, enhancing and adding value to the place, making its target audience interested in getting to know the product. The study aims to identify the marketing strategies carried out by the public and private sector for the development of the municipalities of Alto Caparaó, Dores do Rio Preto and Espera Feliz, more specifically to verify the performance, thus identifying the actions taken and suggesting which ones could still be applied. The methodology applied was defined as descriptive as to means, qualitative, with bibliographic research and interviews with structured script, with the Secretaries of Tourism of the three municipalities. As a result, respondents reported actions taken by municipalities that directly and indirectly impact local socioeconomic development in the region. It was noted that the municipalities have a strong partnership to strengthen tourism throughout the region and stressed that it is important to keep tourists as long as possible, including enjoying all the attractions available, contributing to the growth of satisfaction to all business spheres of the counties. 


\section{Introdução}

O mercado para visitantes tem crescido muito nas últimas décadas, tanto no mercado de negócios, como o de lazer. A oferta de produtos e serviços vem crescendo cada dia mais, as pessoas procuram sempre novas alternativas para suprir suas necessidades e analisam qual a melhor maneira que serão atendidas (KOTLER et al., 2006).

Em se tratando de marketing de lugares as coisas não são diferentes, o consumidor demonstra uma expectativa muito além do que um simples passeio ou uma visita aos pontos turísticos. Sua relação com o lugar desperta uma vivência e uma experiência do contato direto com a cultura, a gastronomia e o bioma da região, até mesmo os atrativos econômicos.

Tendo em vista a forte influência do marketing sobre as decisões dos consumidores, o marketing de imagem, de atrações, de infraestrutura e de pessoas são algumas das estratégias que podem ser desenvolvidas para obter os resultados. A diversificação de atrativos faz com que o turista e empreendedores tenham interesses nesses locais. De acordo com Kotler (2000) o maior desafio dos profissionais de marketing que atuam no setor de serviços é transformar algo intangível em um benefício tangível, com qualidade e valorizado pelos clientes. Em se tratando do turismo de lugares, ecoturismo, turismo de aventura e outros, podemos ver uma forte ascensão nesse tipo de turismo, pois o marketing relacionado ao mesmo tem sido muito trabalhado nos tempos atuais, principalmente em locais que tenham um forte potencial para tal finalidade e que muitas das vezes estavam adormecidos, esquecidos, sem incentivos ou que tenham seus reais potenciais despercebidos.

Ao analisar as propostas de marketing de três dos municípios que fazem parte do circuito turístico da Serra do Caparaó é possível ter uma noção de quanto e como os municípios estão trabalhando junto à iniciativa privada para que possam desenvolver uma economia sustentável a partir do turismo e toda cadeia ligada a ele.

O presente estudo tem como objetivo identificar as estratégias de marketing realizadas pelo setor público e privado para o desenvolvimento dos municípios de Alto Caparaó, Dores do Rio Preto e Espera Feliz. Para tanto, mais especificamente buscou-se verificar a atuação da iniciativa privada e de órgãos do setor público, identificando assim as ações realizadas e sugerir quais ainda poderiam ser aplicadas.

Logo, vendo a importância das estratégias para obtenção de melhores resultados, justifica-se desenvolver esta pesquisa e contribuir de alguma forma para que essas ações sejam aplicadas, com o propósito de que a atividade turística prospere e junto a ela uma economia regional crescente, ações de marketing bem coordenadas que podem 
potencializar a visibilidade da região e retornos financeiros para o município, bem como geração de empregos e desenvolvimento local.

\section{Referencial Teórico}

\subsection{Marketing}

O Marketing sempre esteve presente em nossas vidas, pois atua na identificação e promoção da satisfação das necessidades humanas e sociais. Apesar da origem da palavra ser inglesa, o marketing se popularizou através de práticas mercadológicas dos Estados Unidos.

Para Kotler (2000) marketing é a ciência e a arte de explorar, criar e entregar valor para satisfazer as necessidades de um mercado alvo com lucro. O marketing reúne todo o processo de atividades de planejamento, concepção e finalização, buscando a satisfação das necessidades dos clientes. Marketing não consiste apenas em vender um produto, ele envolve todo um processo que vai da produção, logística, comercialização e o pós-venda do produto ou serviço ofertado conseguindo assim, a fidelidade do cliente (KOTLER et al, 2006).

Para Rocha e Christensen (1999, p. 15) o "marketing é uma função gerencial, que busca ajustar a oferta da organização a demandas específicas do mercado, utilizando como ferramental um conjunto de princípios e técnicas." Para Churchill (2005, p. 4), "marketing é o processo de planejar e executar a concepção, estabelecimento de preços, promoção e distribuição de ideias, produtos e serviços a fim de criar trocas que satisfaçam metas individuais e organizacionais".

\subsubsection{Mix de Marketing (Os 4Ps)}

Kotler e Amstrong (2007, p. 06) dizem que "o marketing consiste em ações que levem à construção e manutenção de um relacionamento de troca de desejos com um público-alvo em relação a algum produto, serviço, ideia ou outro objeto". Para os autores, uma boa gestão de relacionamento com o cliente, cria o encantamento necessário para que eles se tornem fieis e potenciais divulgadores da empresa.

É relevante para os 4ps do marketing: produto, preço, praça e promoção, em que este ferramental contribui para que a organização se aproxime dos clientes e atenda suas necessidades.

Para Kotler e Armstrong (2007, p. 200) produto é "algo que pode ser oferecido a um mercado para apreciação, aquisição, uso ou consumo e para satisfazer um desejo ou uma necessidade". Referente aos serviços, Las Casas (2002, p. 17) afirma que "constituem uma transação realizada por uma empresa ou por um indivíduo, cujo objetivo não está associado à transferência de um bem". 
Ainda Las Casas (2009, p. 217), descreve que "o preço ajuda a dar valor às coisas e representa uma troca pelo esforço feito pela empresa vendedora através da alocação de recursos, capital e mão-de-obra dos produtos comercializados". Para Kotler e Armstrong (2007) o marketing moderno exige mais do que apenas desenvolver um bom produto, colocar um preço competitivo e à disposição dos clientes.

De acordo com Kotler (1998), promoção é o conjunto de ações que estarão incidindo sobre certo produto e/ou serviço, de forma a estimular a sua comercialização ou divulgação. A praça é definida como canal de distribuição, é o caminho percorrido pelo produto até chegar ao consumidor. Armstrong e Kotler (2007, p. 305) definem como "um conjunto de organizações interdependentes que ajudam a tornar um produto ou serviço disponível para o consumo ou uso por um consumidor final ou usuário organizacional."

\subsection{Marketing de Lugares}

Nos últimos anos vem crescendo os estudos sobre o marketing de lugares. Podemos levar em consideração as mudanças socioeconômicas ocorridas nos últimos anos. Assim os países, estados e cidades passam a ser vistos não apenas como um lugar para morar ou viver, mas como um produto que precisa ser divulgado para que as pessoas possam ter contato com os benefícios que ali se encontram para a sua satisfação.

Segundo Kotler (2005, p. 126), "Uma empresa tem por objetivo oferecer algo de maneira diferente e melhor, para que o mercado-alvo venha a preferi-lo e até mesmo pague um preço mais alto por ele".

É muito importante levar em consideração que as políticas desenvolvidas para atrair investimentos públicos e privados, devem ser administradas de forma consciente e conjunta, pois um país, estado, cidade ou região, não mais será vista apenas como um lugar, mas como uma marca.

Para Kotler et. al. (2006), as estratégias de marketing de lugares influenciam as decisões de seus potenciais clientes onde envolve compras, investimentos, viagens e até mesmo na mudança de domicílio.

Marketing de lugares significa projetar um lugar para satisfazer as necessidades do seu público-alvo. Logo, este tem sucesso quando os cidadãos, os negócios e as empresas estão satisfeitos com as estratégias mercadológicas implementadas para projetar um destino. A satisfação dos visitantes, turistas e investidores também, devem ser levadas em conta e a estratégia de marketing de lugares deve afetar todas as partes interessadas. (KOTLER et al, 2006).

A imagem de um lugar é construída através de crenças, ideias e percepções que as pessoas têm do local e que variam de indivíduo para indivíduo. Portanto, para que um lugar 
tenha uma imagem atrativa para investidores e visitantes, é preciso usar estratégias para que eles enxerguem a imagem e o potencial do lugar (KOTLER et al, 2006).

Para alguns profissionais de marketing a promoção de um lugar é o fator mais importante, mas segundo Kotler a promoção em si é uma das tarefas menos importante. "Marketing de lugares significa projetar um lugar de modo que satisfaça as necessidades do mercado-alvo." (KOTLER et al, 2006, p. 148). Quando todos os envolvidos, desde empresas, investidores, visitantes e cidadãos estão satisfeitos dentro de suas expectativas e necessidades. O lugar a ser projetado precisa de um plano de desenvolvimento sólido, bem estruturado, para que seja atrativo, com qualidade e valores estéticos.

Para o desenvolvimento e crescimento do local é preciso ter uma infraestrutura que atenda às necessidades de visitantes e pessoas da localidade. "Embora uma infraestrutura excelente e bem mantida não possa garantir o crescimento da comunidade, sua ausência é um problema sério." (KOTLER et al, 2006, p. 155). Com uma infraestrutura inadequada, o crescimento econômico do lugar fica comprometido, pois impede o movimento de informações e de pessoas. Por isso é preciso ter uma manutenção constante que esteja atualizada e rastreada periodicamente. "Cada vez mais, a avaliação das necessidades e a gestão da infraestrutura estão unidas por uma nova ênfase no desempenho, não apenas na construção." (KOTLER et al, 2006, p. 158). O planejamento estratégico precisa de escolhas inteligentes e criativas.

\subsection{O Turismo na Serra do Caparaó}

A Serra do Caparaó está situada na Zona da Mata de Minas Gerais e no Sul do Espírito Santo e abriga em seu território o Parque Nacional do Caparaó, com 31.800 hectares. O Parque foi criado em 1964 para proteger belas cachoeiras, uma vegetação própria do clima de serra e o principal atrativo turístico da região o Pico da Bandeira, que com seus 2982 metros de altitude também atrai montanhistas e aventureiros.

A Serra destaca-se não apenas pelo atrativo turístico e econômico para a região, mas também pela produção de diferentes tipos de cafés, inclusive alguns com premiações no Brasil e presentes em vários países do mundo, pela sua qualidade. A região conta com várias cafeterias, restaurantes com a culinária típica mineira, hotéis, pousadas, casas de shows e outros empreendimentos que são um capítulo à parte no entretenimento dos turistas que procuram a Serra Do Caparaó.

As cidades de Alto Caparaó, Dores do Rio Preto e Espera Feliz são cidades com grande importância no turismo da região, pois se destacam por abrigar em seu âmbito belas cachoeiras, cafeterias e ainda as portarias de entrada do Parque Nacional do Caparaó que dá acesso ao Pico da Bandeira. 


\subsubsection{Municípios Pesquisados}

Situada na zona da mata mineira, Espera Feliz possui uma extensão territorial de 317.638 km², segundo dados do IBGE-2010, uma população estimada de 22.856 habitantes. O município hoje tem sua economia baseada na cafeicultura, turismo e no comércio. Nos últimos anos Espera Feliz vem se destacando no cenário nacional por produzir cafés de altíssima qualidade, com isso o turismo da cidade vem crescendo com a procura desses cafés. Destaca-se também o privilégio que o município tem por conter em seu território belíssimas cachoeiras que atrai muitas pessoas para visitá-las. Para receber esses turistas 0 município conta atualmente com hotéis, pousadas, restaurantes e cafeterias.

A cidade de Alto Caparaó possui uma população de 5.297 habitantes em uma área de 103.690 km², segundo dados do IBGE-2010. Grande parte dessa população reside em pequenas propriedades rurais de onde é extraída uma das maiores riquezas da região, o café. Este produto é o principal propulsor da economia da cidade, gerando empregos diretos e indiretos para o município. Outra importante fonte de renda do município de Alto Caparaó é o turismo, uma vez que o município abriga em seu território a sede administrativa do Parque Nacional do Caparaó, e uma das portarias que dá acesso ao parque e faz com que a cidade receba um elevado número de turistas vindos de todas as regiões do país e do exterior. Para receber esses turistas a cidade de Alto Caparaó conta com bons hotéis, pousadas, restaurantes e cafeterias e ainda com um grande número de cachoeiras que com suas belezas encantam todos que as visitam, a cidade conta também com guias turísticos que dão todo o apoio ao turista.

O município de Dores do Rio Preto é constituído por três distritos, Dores Do Rio Preto, Mundo Novo e São Raimundo Da Pedra Menina. Possui cerca de 6.397 habitantes, distribuídos em uma área territorial de 159.298 km² segundo dados do IBGE-2010. Dores do Rio Preto, nos últimos anos, tem ganhado destaque por produzir cafés especiais, que tem atraído um grande número de turistas para experimentar e adquirir esse produto. Outro importante atrativo turístico para o município é a portaria do Parque Nacional do Caparaó que dá acesso a subida ao Pico da Bandeira pelo território capixaba e as exuberantes cachoeiras que também vêm tendo grande importância e impacto para os visitantes.

Com os empreendedores cada dia mais antenados com o crescimento turístico do município, vem aumentando investimentos na construção e na melhoria das estruturas para recepção desses turistas, como restaurantes, cafeterias, hotéis e pousadas para que isso seja também um atrativo a mais para o município. 


\section{Procedimentos Metodológicos}

Para a realização da pesquisa, a metodologia foi definida, quanto aos fins, como descritiva. "Pode-se dizer que ela está interessada em descobrir e observar fenômenos, procurando descrevê-los, classificá-los e interpretá-los" (VIEIRA, 2002, p. 65), e o método escolhido, quantos aos meios, foi a abordagem qualitativa, com utilização de estudo de caso múltiplos, a partir da coleta de dados com realização de entrevistas com roteiro semiestruturado com o intuito de identificar as estratégias de marketing realizadas pelo setor público e privado para o desenvolvimento dos municípios de Alto Caparaó, Dores do Rio Preto e Espera Feliz.

Foi realizada uma pesquisa bibliográfica sobre o tema de marketing dando embasamento para o desenvolvimento do estudo e uma pesquisa sobre a região da Serra do Caparaó para a tomada de decisão quanto aos processos utilizados para a coleta de dados da pesquisa de campo, permitindo que os objetivos fossem alcançados.

Contudo, foram realizadas entrevistas com os secretários de turismo das cidades de Alto Caparaó, Dores do Rio Preto e Espera Feliz durante o período de 26 de setembro a 07 de outubro de 2019. Após a realização das entrevistas, foram apurados os resultados, permitindo uma análise e discussão dos dados e apresentando a conclusão com recomendações e sugestões aos municípios, e para trabalhos vindouros sobre o tema.

\section{Apresentação e Análise dos Resultados}

De acordo com os objetivos, a pesquisa buscou identificar as estratégias de marketing realizadas pelo setor público e privado para o desenvolvimento dos municípios de Alto Caparaó, Dores do Rio Preto e Espera Feliz. Foram realizadas entrevistas com secretários do turismo, contudo, serão apresentados como Secretário de Turismo A, Secretário de Turismo B e Secretário de Turismo C para maior discrição.

Inicialmente, quando questionados em quais ações têm sido feitas para atrair os turistas e fazer com que tenham interesse em voltar, o Secretário de Turismo A relatou, que como o município tem o turismo ecológico bem consolidado e com um grande número de visitantes, uma das ações seria não necessariamente aumentar o número de turistas, mas sim fazer com que ele permaneça mais tempo na região, gerando mais recursos e menos impacto. Continuou em seu relato que o município investe pesado no turismo rural, pois as produções de cafés especiais são reconhecidas em todo o mundo e vem atraindo uma gama de turistas para a região.

Ainda nesta questão, o Secretário de Turismo B relatou que, o município vem trabalhando na criação de circuitos para a prática de esportes de aventuras, ecoturismo, um circuito voltado para a rota de cafés especiais e a mais recente, uma novidade na região, que é a observação de pássaro. Menciona, ainda, que o município proporciona eventos 
voltados para cultura, esporte e gastronomia fazendo uma diversificação de atividades para que esse turista venha, permaneça, volte e ainda divulgue a região.

Já o Secretário de Turismo $C$ relata que, o conjunto de municípios que fazem parte do circuito turístico, juntamente com o Ministério do Turismo, desenvolvem ações de marketing e planejamento. Também desenvolvem roteiros voltados para toda a região, além disso, o município individualmente ou com parceria da iniciativa privada trabalha 0 calendário de eventos para que não haja períodos isolados e sem atratividade, influenciando para um fluxo contínuo de turista durante todo o ano. Quando questionados como o município tem ajudado os empresários no que diz respeito à infraestrutura para receber os turistas, o Secretário A revela que não se compromete diretamente na infraestrutura para atendimento aos turistas, mas incentiva a iniciativa privada a desenvolver-se para melhor atendê-lo, entretanto, em parceria com o SEBRAE e SENAC, realizam cursos de capacitação no município sempre priorizando atender os turistas da melhor forma possível. Por sua vez, o Secretário B relata que o município, em parceria com o governo estadual, vem trabalhando no principal gargalo para o turismo da região, a sinalização e conservação das estradas municipais e estaduais que dão acesso ao parque. O município vem também desenvolvendo a infraestrutura, paisagismo, parte ecológica, questão da acessibilidade e vários projetos futuros para a recepção do turista. Já o secretário $\mathrm{C}$, relatou que o município é o grande indutor do turismo, e que se trabalha a infraestrutura da cidade com melhorias de estradas, sinalização, inclusive melhorias dos atrativos construídos para a recepção dos turistas.

Quando questionados se existe algum projeto de capacitação para o atendimento e recepção do turista disponibilizado pelo município, o Secretário A diz ter uma parceria entre o município e órgãos como o SENAR e o instituto Aprecia, que desenvolvem projetos de capacitação de mão de obra e bom atendimento à população local para melhor atender os turistas. O Secretario B disse que o município juntamente com o SENAR e SEBRAE, tem desenvolvido projetos com intuito de capacitar a população local, para atendimento e recepção dos turistas, projetos que envolvem princípios básicos como higiene, bom atendimento e projetos de capacitação e desenvolvimento de empreendimentos gastronômicos e financeiros dentre outros. O Secretário $C$ relata que o município trabalha junto ao SENAR e SEBRAE para expandir o turismo, buscando capacitar os produtores não somente na área de produção, mas também beneficiamento, gerenciamento a recepção de turistas em suas propriedades, pois assim conseguem aumentar a diversificação do seu negócio e aumentar sua renda.

Quando perguntados quais os canais de divulgação o município tem usado para atrair turistas, investidores e empreendedores, o Secretário A relata que o município tem trabalhado muito no desenvolvimento de sites, mídias sociais, documentários em redes de 
televisão, mídias espontâneas e junto às feiras, que são um dos principais meios de divulgação do setor turístico da região. O secretário $B$ relata que o município faz o uso de todas as mídias possíveis para a divulgação do seu trabalho, sites, jornais, revistas e todas as mídias espontâneas e sociais, levando informações ao maior número de pessoas possíveis, afim de sempre aumentar a demanda do setor para a região. Em se tratando de canais de divulgação, o entrevistado Secretário de Turismo $\mathrm{C}$ dá ênfase às feiras, salões de negócios e eventos púbicos direcionados ao café.

Os entrevistados foram perguntados se os meios de divulgação feitos pelo setor público têm atendido às perspectivas dos empreendedores, segundo o Secretário A o município disponibiliza as primeiras informações, mas deixa a cargo dos empreendedores a resposta para a referida pergunta. $O$ secretário $B$, relata que a divulgação é de fato bemsucedida, pois a demanda tem sido crescente por essa região. Ainda, segundo o entrevistado, a região foi um dos destinos mais procurados no estado do Espírito Santo no ano de 2018. O entrevistado Secretário C relata não ter ações efetivas na área de marketing, mas sente a necessidade de implantar, a fim de promover mais a região, buscando qual seria a melhor mídia a ser trabalhada para que se tenha uma ação de marketing forte e efetiva.

Quando perguntados se a prefeitura contribui de alguma forma na realização de eventos, o Secretário A disponibilizou a informação de que seu município tem um calendário de eventos anuais, e que realizam eventos relacionados a entretenimentos, esportes, esportes de aventura, cultural e religioso e, também, feiras direcionadas à cultura cafeeira especificamente a de cafés especiais. O secretário $B$ relata que o município conta com um calendário de festa e eventos anuais e disponibiliza toda a infraestrutura para feiras voltadas para o setor artesanal, gastronômico e da agroindústria do município e região. O secretário C menciona que o município pratica o calendário de eventos dando ênfase aos eventos em expansão e direcionado ao desenvolvimento do turismo e da economia da cidade.

Quanto à percepção sobre o crescimento do turismo na região, foram questionados quais as expectativas para os próximos anos. O Secretário $A$ menciona que nos últimos cinco anos houve um crescimento de quase $150 \%$ no número de turistas que visitam a cidade, mas que esse aumento também traz impactos negativos, esses não revelados por ele. O Secretário B diz que a demanda vem crescendo, quando se trata de aumento da procura dos turistas para desfrutar das cachoeiras, cafeterias, restaurantes, além de pesquisadores e participantes das feiras de agronegócios. Segundo o entrevistado Secretário $C$, relata que vê um crescimento e um desenvolvimento do turismo e que se dá em grande parte devido a produção de cafés especiais, fator que agrega ao turismo nacional e internacional, já não sendo exclusivamente o Parque Nacional o grande protagonista do turismo na região. 
Quando questionados sobre a existência de alguma promoção/divulgação diferente para baixas e altas temporadas, o Secretário A menciona que em alta temporada se concentra muito na esfera privada, já existe uma promoção e divulgação absorvendo todo o fluxo de turistas. Continua em seu relato que em baixa temporada, existem ações do governo municipal, o qual se faz um trabalho relevante para atrair os turistas, como os calendários de eventos festivos no município. Já o Secretário B relata que atualmente, não há uma alta ou baixa temporada e que o fluxo de turistas é estável tanto no verão quanto no inverno, devido à diversificação de atrativos da região. $O$ secretário $C$ relata que não se percebe uma diferenciação de alta e baixa temporada, pois, as belezas cênicas da região proporcionam um fluxo de turistas em toda a região.

Finalizando as entrevistas, foram questionados como os Secretários veem os municípios vizinhos, se como parceiros ou concorrentes. O Secretário de Turismo A relatou que a palavra de ordem é união, que os municípios têm uma forte parceria entre si para juntos fortalecerem o turismo de toda a região e ressaltando ser importante manter os turistas o maior tempo possível, inclusive desfrutando de todos os atrativos disponibilizados pelos municípios vizinhos. O Secretário de Turismo B mencionou ter uma total parceria com todos os municípios tanto do Espírito Santo quanto os de Minas Gerais, pois todos os roteiros são desenvolvidos para beneficiar a região da Serra do Caparaó, com isso gerando um aumento significativo no número de empregos diretos e indiretos e também no número de empreendimentos que da mesma forma estão ligados direto ou indiretamente ao setor turístico. Já o Secretário de Turismo $\mathrm{C}$, relatou que vê os municípios vizinhos como parceiros devido à proximidade territorial, além das estratégias voltadas para o turismo e o desenvolvimento local e da região.

\section{Conclusão}

As entrevistas realizadas com os representantes dos municípios, explanam a importância da maximização produtiva de cafés especiais para o turismo nas regiões do Caparaó mineiro e capixaba. As belezas atrativas da região, amparadas pelo Parque Nacional do Caparaó, deixaram de ser as únicas variáveis de procura por turistas nacionais e internacionais e dividem hoje, espaço ponderado com as propriedades produtoras dos famosos e premiados cafés gourmets do Caparaó, algumas delas, com cafeterias próprias. Cientes disso, com otimismo futuro, os municípios em estudo reconhecem a importância de incluir as propriedades produtoras dos grãos especiais em suas rotas turísticas e trabalharem no sentido de expandir as melhorias estruturais em estradas rurais que permeiam tais propriedades, bem como sinalizações, oferecendo melhores parâmetros de acesso e localização aos visitantes. 
Enquanto os municípios de Dores do Rio Preto e Espera Feliz buscam alternativas para maximizar a procura de visitantes pela região que integram o Parque Nacional que abriga o Pico da Bandeira, Alto Caparaó enxerga que a permanência de seus visitantes por mais tempo na região, ao invés de uma alta rotatividade turística, traz melhores compensações financeiras e ambientais, daí a necessidade de se trabalhar em conjunto com os demais municípios, apresentando aos visitantes, todas as atratividades que a região tem a oferecê-los, aumentando a permanência dos mesmos pelas cidades que integram o Caparaó.

É de conhecimento que o atendimento é tangível na prestação de serviços, o que dispõe de capacitação para melhores relações com o público-alvo. Neste sentido, os Secretários de Turismo dos municípios de Alto Caparaó, Dores do Rio Preto e Espera Feliz, relataram que o crescimento turístico da região, demanda melhores capacitações das mãosde-obra responsáveis pelo atendimento ao público visitante. Diante desta demanda por capacitação, os referidos municípios, com benevolência, reconhecem a importância de mais informações, com finalidade de uma melhor prestação de apoio às empresas, através de parcerias e de projetos junto a órgãos como SENAR e SEBRAE, responsáveis por capacitar pessoas para atendimentos formais.

Atualmente, as mídias sociais tornaram-se cada vez mais próximas às pessoas e são capazes de estabelecer comunicações com públicos extensos. Com isso, sabiamente, os Secretários relataram que as mídias, além das espontâneas, podem apresentar aos turistas, investidores e empreendedores, os recursos de atratividades geográficas, ambientais e econômicas que a região oferta, objetivando ganhos financeiros com a presença destes em seus respectivos municípios.

As pessoas que visitam o Caparaó se pulverizam por toda região, em busca de atrativos que as agrade. Com isso, em unanimidade, relataram que trabalham em conjunto, objetivando potencializar a presença temporária dos turistas pela região, o que segundo eles, traz benefícios econômicos aos seus municípios, gerando empregos e desenvolvimento.

Portanto, a pesquisa contribuiu para ressaltar que com a pluralização de pessoas pela região, as oportunidades empreendedoras se intensificam de forma direta e indireta, que elevam a circulação de capital financeiro à região, contribuindo com o crescimento de satisfação a todas as esferas comerciais dos municípios, o que gera desenvolvimento socioeconômico. 


\section{REFERÊNCIAS}

CHURCHILL, Gilbert A. J. Marketing: Criando valor para os clientes. São Paulo. Editora Saraiva, 2005.

IBGE, Instituto Brasileiro de Geografia e Estatística. Disponível em:<https://cidades.ibge.gov.br/brasil/es/dores-do-rio-preto/panorama>. Acesso em: 15 de Junho de 2019.

Disponível em: <https://cidades.ibge.gov.br/brasil/mg/alto-caparao/panorama>. Acesso em: 15 de Junho de 2019.

Disponível em:<https://cidades.ibge.gov.br/brasil/mg/espera-feliz/panorama>. Acesso em: 16 de Junho de 2019.

KOTLER, Philip. Administração de marketing: Administração de Marketing: a Edição do Novo Milênio. 10ª Edição. São Paulo. Editora Prentice Hall, 2000.

Análise, planejamento, implementação e controle. 5ª Edição. São Paulo. Editora Atlas, 1998

KOTLER, P. ARMSTRONG, G. Princípios de marketing. Tradução Cristina Yamagami. 12 Edição. São Paulo. Pearson Prentice Hall, 2007.

KOTLER, Philip, et. al. Marketing de lugares: Como conquistar crescimento de longo prazo na América Latina e Caribe. Tradução: Ruth Bahr. São Paulo. Editora Prentice Hall, 2006.

KOTLER, Philip. O marketing sem segredos. Porto Alegre: Editora Bookman, 2005.

LAS CASAS, Alexandre Luzzi. Marketing: conceitos, exercícios, casos. 8aㅡ Edição. São Paulo. Editora Atlas, 2009.

Marketing de Serviços. 3를 Edição. São Paulo. Editora Atlas, 2002.

ROCHA, A. CHRISTENSEN, C. Marketing, teoria e prática no Brasil. 2ª Edição. São Paulo. Editora Atlas, 1999.

VIEIRA, Valter Afonso. As tipologias, variações e características da pesquisa de marketing. Rev. FAE, Curitiba, v.5, n.1, p.65, jan./abr. 2002 